\title{
Natural dead sea salt and retrospective dosimetry
}

\author{
Norfadira Binti Wahib ${ }^{1,2}$ - S. F. Abdul Sani ${ }^{1}$ @ Ain Ramli $^{1}$ - S. S. Ismail ${ }^{1} \cdot$ Muhammad Hussin Abdul Jabar $^{1}$. \\ M. U. Khandaker ${ }^{1,2} \cdot$ E. Daar $^{3} \cdot$ K. S. Almugren ${ }^{4} \cdot$ F. H. Alkallas ${ }^{4}$ D. A. Bradley ${ }^{2,5}$
}

Received: 29 January 2020 / Accepted: 29 April 2020

(c) Springer-Verlag GmbH Germany, part of Springer Nature 2020

\begin{abstract}
Accidents resulting in widespread dispersal of radioactive materials have given rise to a need for materials that are convenient in allowing individual dose assessment. The present study examines natural Dead Sea salt adopted as a model thermoluminescence dosimetry system. Samples were prepared in two different forms, loose-raw and loose-ground, subsequently exposed to ${ }^{60}$ Co gamma-rays, delivering doses in the range 2-10 Gy. Key thermoluminescence (TL) properties were examined, including glow curves, dose response, sensitivity, reproducibility and fading. Glow curves shapes were found to be independent of given dose, prominent TL peaks for the raw and ground samples appearing in the temperature ranges $361-385{ }^{\circ} \mathrm{C}$ and $366-401^{\circ} \mathrm{C}$, respectively. The deconvolution of glow curves has been undertaken using GlowFit, resulting in ten overlapping first-order kinetic glow peaks. For both sample forms, the integrated TL yield displays linearity of response with dose, the loose-raw salt showing some $2.5 \times$ the sensitivity of the ground salt. The samples showed similar degrees of fading, with respective residual signals 28 days post-irradiation of $66 \%$ and $62 \%$ for the ground and raw forms respectively; conversely, confronted by light-induced fading the respective signal losses were $62 \%$ and $80 \%$. The effective atomic number of the Dead Sea salt of 16.3 is comparable to that of TLD-200 ( $\left.\mathrm{Z}_{\text {eff }} 16.3\right)$, suitable as an environmental radiation monitor in accident situations but requiring careful calibration in the reconstruction of soft tissue dose (soft tissue $Z_{\text {eff }}$ 7.2). Sample luminescence studies were carried out via Raman and Photoluminescence spectroscopy as well as X-ray diffraction, ionizing radiation dependent variation in lattice structure being found to influence TL response.
\end{abstract}

Keywords Dead sea salt $\cdot$ Loose- raw $\cdot$ Loose- ground $\cdot$ Thermoluminescence $\cdot$ Retrospective dosimetry $\cdot$ Spectroscopy characterization

\section{Introduction}

The present work concerns retrospective dosimetry, having in mind needs arising from the advent of unplanned emission/release situations, most prominently in accident situations resulting in widespread dispersal of radioactive

S. F. Abdul Sani

s.fairus@um.edu.my

1 Department of Physics, University of Malaya, 50603 Kuala Lumpur, Malaysia

2 Centre for Biomedical Physics, School of Healthcare and Medical Sciences, Sunway University, 47500 Bandar Sunway, Selangor, Malaysia

3 Department of Physics, The University of Jordan, Amman 11942, Jordan

4 Department of Physics, Princess Nourah Bint Abdulrahman University, Riyadh, Saudi Arabia

5 Department of Physics, University of Surrey, Guildford, Surrey GU2 7XH, UK materials (see for instance, Bradley 1986). Under particular circumstances, the latter can potentially lead to substantial doses to the population (sub-Gy and more), also possibly involving large numbers of individuals. In mind are steps towards the evaluation of exposures to those who reside or who otherwise might be going about their business within the locality of nuclear installations (e.g. within a few $\mathrm{km}$ ) suffering a loss in control of the radioactivity inventory. Ostensibly, such accidents are highly unlikely to occur, relating to well-designed, highly controlled, defence in depth installations. Within such precept, the distribution of personal dosimeters to non-radiation workers is neither 